\title{
Chapter 5 \\ Interactional Analysis: A Method \\ for Analysing Mathematical Learning \\ Processes in Interactions
}

\author{
Marcus Schütte, Rachel-Ann Friesen and Judith Jung
}

\begin{abstract}
When looking at learning processes from an interactionist perspective, interaction between individuals is seen as central for learning. In order to understand and describe these interactions and therefore the learning processes, a method was developed in mathematics education grounded in the theory of Symbolic Interactionism and Ethnomethodology - the Interactional Analysis. In this chapter, at first the underlying theory for the Interactional Analysis is presented, before the steps of the method are explained, giving an example for each step. Findings of research using this method have been widely published, however, the method has not been described in depth in English yet. Therefore, this chapter makes a valuable contribution for enabling this method to be more accessible for an international research community, as well as helping international researchers understand the findings produced by using this method more clearly.
\end{abstract}

Keywords Methodology - Interactional analysis · Reconstructive-interpretive research • Interactionism - Qualitative research

\subsection{Introduction}

Three children-Mira, Franka and Emilio - are sitting on a carpet in a classroom and are working together on a task. They have just placed ten rods, which are each made up out of ten wooden beads, in one long row. After taking wooden cards with tens on them from a plastic bag, Mira says "ten divided by three" $<01>$ and Franka asks her what "divided" means. After Mira gives Franka the example that "six

\footnotetext{
M. Schütte $(\bowtie) \cdot$ R.-A. Friesen · J. Jung

Technische Universität Dresden, Dresden, Germany

e-mail: marcus.schuette@tu-dresden.de

R.-A. Friesen

e-mail: rachel-ann.friesen@tu-dresden.de

J. Jung

e-mail: judith.jung1@tu-dresden.de

(C) The Author(s) 2019 
divided divided by three is three"<05>, Franka and Mira have the dialogue in Table 5.1.

When examining this kind of interaction between pupils from the perspective of mathematics education research, many questions arise: What is the relevance of the material being used? What mathematical idea of division do the participating children show? In what way is mathematical learning taking place within this interaction? For finding answers to many of these kind of questions, the method of Interactional Analysis provides a useful analytical tool, however, the main focus is on the exploration of the last question in various differentiations. Depending on the specific interest of a study, this would be further specified, with the research-leading questions normally being the following: How does the topic (of division) develop between Franka and Mira? How are these two pupils negotiating this mathematical topic in the interaction? In what way are Mira and Franke able to participate in this group work? Specifically for this interaction between Mira and Franka, the Interactional Analysis allows us to describe how the two pupils negotiate the theme of division, which mathematical ideas they express and to what extent these become attuned to each other in the interaction.

Hence, the Interactional Analysis is an empirical social-scientific research method that can be used to evaluate collected data on the reality of our social experiences. It was developed within theoretical interactional approaches of the qualitative research paradigm, and in contrast to quantitative research methods serves not to review hypotheses with defined variables, but to provide a comprehensive, holistic view on social interactions and, in the interpretive approach, to generate new assumptions and further develop theories. The method is grounded in the following assumptions: Diverse realities of social experiences exist alongside each other and can only be investigated in the holistic, contextualised reconstruction of the points of view and modes of action of the actors in interactions. Concerning scientific theories, the interaction theory is based on social-constructivist, symbolic-interactionist and phenomenological theories of cognition. In this, the theoretical assumptions of Symbolic Interactionism (Blumer 1969) and Ethnomethodology (Garfinkel 1967) are particularly significant for comprehending the method of the Interactional Analysis on a basic level. The theoretical foundations of these approaches will, therefore, be presented hereafter.

According to the basic assumptions of Symbolic Interactionism, reality presents itself to every individuals as their interpretation of what is going on around them and the meaning that they ascribe to it. Symbolic Interactionism thus concentrates on the ways individuals develop, transform and potentially consolidate their ideas about reality in interactions assisted by the use of symbols. In this perspective, reality is neither set nor given per se, but rather emerges for each individual in an individual process of interpretation. Meaning here refers not to the degree of significance for the individual, but to the meanings which everyday things have for the individuals. Therefore, things or objects do not contain meaning naturally: it only develops by individuals ascribing meaning to it. These individual processes of interpretation unfold in exchanges with other individuals. Hereby, the social 
Table 5.1 Transcript $<9-20>$

\begin{tabular}{l|l|l|l|l}
\hline 09 & $02: 12$ & $\#$ & Franka & $\begin{array}{l}\text { eh. dividing six is three [holds left hand horizontally and } \\
\text { moves right hand, which is held vertically, up and down] }\end{array}$ \\
\hline 10 & $02: 15$ & & Mira & Yes \\
\hline 11 & $02: 15$ & & Franka & ah/that's easy \\
\hline 12 & $02: 17$ & & Mira & And ten divided by three/(4) doesn't work\ yes it does. Wait \\
\hline 13 & $02: 25$ & & Franka & eh now I don't understand\# \\
\hline 14 & $02: 27$ & $\#$ & Mira & Wait \\
\hline 15 & & $<$ & Franka & Now I don't understand \\
\hline 16 & & $<$ & Mira & Ten divided by three is three six \\
\hline 17 & $02: 31$ & & Franka & $\begin{array}{l}\text { You cut the ten [rubs her right and her left hand vertically } \\
\text { against each other] }\end{array}$ \\
\hline 18 & & $<$ & Mira & \begin{tabular}{l} 
Three six nine \\
\hline 19
\end{tabular} \\
\hline 20 & $02: 33$ & $\#$ & Mira & $\begin{array}{l}\text { Then five are left over. You cut\# } \\
\text { carpet] } \text { so someone } \text { has to have one number more }\end{array}$ \\
\hline
\end{tabular}

The rules for transcription used in this chapter are presented in Sect. 5.5.3.

interaction represents the central component in the theory of Symbolic Interactionism (Blumer 1969; Keller 2012; Turner 1988).

Social interaction, like the negotiation of Mira and Franka presented above, in which meanings are collectively negotiated, can, from the perspective of Symbolic Interactionism, be seen as a constituent of learning processes. As a consequence, Symbolic Interactionism contradicts notions that mathematical objects contain meaning only inherently in their form or internal structures. Instead, a die only becomes a die when the people involved in the interaction negotiate it as such, giving it specific characteristics and naming it.

The ethnomethodological approach based on qualitative empirical research aims to empirically investigate and reconstruct the methods used by members of a society to construct social reality in their everyday lives. These methods are described by Garfinkel (1967) as "ethnomethods". Garfinkel emphasises that talking about actions, e.g. in group discussions or interviews, is totally different to the actions themselves, and that it is therefore crucial to observe everyday actions in their execution. Records of social occurrences/situations of people's everyday lives therefore form the focus of ethnomethodological analyses. Ethnomethodology is not concerned with reconstructing the motives behind actions; instead, the focus of analyses falls upon the emergence of social reality and methods of the social production of order. These methods are not necessarily considered or applied consciously by participants, but nevertheless are familiar to them because they are used routinely (Ingram 2018; Keller 2012).

Specifically, the Interactional Analysis is based on the ethnomethodological Conversational Analysis, an approach developed in the 1960s (Sacks 1998; Sacks et al. 1974). As a fundamental practical principle of the Conversational Analysis, 
interactional sequences are audio-recorded in real time, the recorded data is then transcribed and afterwards the transcripts are sequentially analysed. Therefore, the internal structure of the interaction, how it is developed step by step, can be investigated.

\subsection{Mathematics Learning from an Interactionist Perspective}

Sociological and social-constructivist approaches to the study of learning processes have gained increasing influence in recent years in the development of theories of content-related mathematical learning (Lerman 2000). This process has also expanded the understanding of mathematics itself as a social cultural technology mediated and constructed by language (Schütte 2014; Sfard 2008; Solomon 2009). Implemented at the end of the 1980s by a group of German and American researchers (Cobb and Bauersfeld 1995a), the social turn was brought into clearer focus in the field of mathematics education via diverse studies using interactionist approaches of interpretive classroom research. Grounded in the (sociological) theory of Symbolic Interactionism and Ethnomethodology, these combined sociological and social-constructivist with subject-educational theories of learning (Bauersfeld et al. 1988).

These studies were explicitly distanced from the previously dominant view that learning was merely an internal psychological phenomenon. The social turn and the inclusion of interactionist aspects of learning and teaching meant a shifting of focus from the structure of objects to the structures of learning processes, and from the individual learner to the social interactions between learners. This transformed understanding of learning led to the development of theories that see meaning, thinking, and reasoning as products of social activity (Bauersfeld et al. 1988). Based on the fundamental assumption of these approaches, i.e. that meaning is negotiated in interactions between several individuals and that social interaction is thus to be understood as constitutive of learning processes, speaking about mathematics with others is in itself to be seen as the "doing" of mathematics and the development of meaning.

According to Cobb and Bauersfeld (1995b), studies that adopt such approaches are based - unlike individualistic approaches to learning in the tradition of Piageton the notion of learning as a process initiated primarily through interaction, which can only be described by tracing the coordination of the mental activities of at least two individuals, as takes place, e.g., in a conversation. Thus, social interaction becomes the focus of attention in these approaches. According to the interactionist perspective, individual processes of interpretation are developed, transformed and stabilised in the exchange with other individuals: while remaining an individual process, learning is nevertheless anchored constitutively in collective activities. Interactionism assumes that an individual is only enabled to do fundamental 
learning steps - these are steps that do not only involve the use or reproduction of existing knowledge - within the social group and on the basis of processes of social interaction between the individuals of this group.

This means that individually learning something new is determined by collective processes which proceed the individual learning. Thus, according to Miller (1986), the exchange with others affords the individual opportunities to systematically move beyond his or her own "limited" abilities, which is only secondarily reflected in individual processes of cognitive restructuring. Older children or adults can certainly learn individually, e.g., by using literature, however, Miller (1986) locates such individualised learning in later phases of human development, meaning in moments of reflexive consolidation of those things originally learnt collectively. Early learning or the conditions for enabling learning in the pre-school period or in primary school are, nevertheless, fundamentally social in nature.

Up to the start of the 2000s, research in this area of mathematics education predominantly took place under the umbrella of interpretive classroom research. Since the most recent work of interpretive classroom research extends the focus from everyday learning of mathematics in school to encompass learning in kindergarten, nursery school and the family, the term "classroom research" thus begins to seem limiting and no longer suitable (Krummheuer 2013; Schütte 2014; Tiedemann and Brandt 2010). In the following, we therefore use the term "interpretive research" and seek to reduce the specific focus on classroom research.

\subsection{Theory Development in Interpretive Research}

Interpretive research represents a kind of umbrella term that refers both to the object of investigation and the methodical approach of the research. At the same time, it implies a theoretical standpoint (Cobb and Bauersfeld 1995b; Bauersfeld et al. 1988; Krummheuer and Naujok 1999). Rather than on a ratified, conceptually anchored mathematics, conceived of as an object, the focus of interpretive research is on the interpretations and interpretive ascriptions which are constantly being produced in the interactions which take place between participants in everyday processes of mathematical learning, for example in school, in the family or in nursery school. Supporters of interpretive classroom research in mathematics education originally sought to orient research more strongly towards describing and "wanting-to-understand" mathematics teaching rather than prescribing and "wanting-to-transform" (Krummheuer 2004). The intention, hereby, was a critical shift away from the hitherto conventional, approaches of classroom research focussing on Subject Matter Didactics. This shift was expressed in the principle of reconstructive research, which places the "[...] 'How' in relation to the functioning of a slice of social reality" at the heart of the investigation, and suppresses the 'What', that is relating to content (Krummheuer 2004, p. 113, translated by the authors). The switch from focusing on the "What" of social reality to looking at the "How" of the construction of this reality is foundational to interactionist approaches 
of interpretive research in mathematics education - although current studies often aspire to reveal potential change in the future through describing current practice in the teaching and learning of mathematics. Through "understanding" individual actions, the overarching goal of interpretive research is therefore to develop empirically grounded, content-rich local theories. In the domain mathematics education, interpretive research is seeking to develop theories concerning the conditions of possibilities for learning of individuals in diverse teaching and learning settings. Overall, the question arises what the relationship of "everyday classroom interactions in mathematics teaching", as an object of investigation, to existing or envisaged theory is? Regarding the relationship between object and theory in interpretive research, Krummheuer (2002) mentions the "unavoidability of theory construction" and draw a link to the potential for the permanent transformation of everyday teaching.

\section{It will be explained that as a research scientist dealing with the domain of social interaction in primary education, one is usually not in the position to cope with an a priori stock of theories, which are sufficiently developed in order to adequately understand a certain classroom situation. In such cases the researcher is facing a specific methodological problem: the necessity for constructing elements of a theory that claim to generate a theory-consistent interpretation of the selected part of reality. (p. 340)}

Naujok (2000), however, limits the scope of the concept of theory, arguing that in many other fields it tends to have global, universalising connotations. Research adopting a reconstructive-interpretive approach does not make such universalising claims for its results (Krummheuer and Naujok 1999). According to Naujok (2000), the theoretical products of interpretive research are "rather to be understood as attempts to explain empirical phenomena and contextual links between them" (p. 32, translated by the authors). As cited in Kelle (1994), Merton (1968) and Blumer (1954) differentiate between two heuristic concepts in their discussion of the hierarchical structure of social-scientific theories and the heuristic significance of their leading assumptions: one has a wide reach but little empirical content and thus limited precision ${ }^{1}$; the other might only be applied in limited fields of social reality, but provides more precise, richer theory. ${ }^{2}$ The hypotheses of interpretive research thus remain beholden to the respective context of the field being investigated but consequently contain empirically rich elements and are internally consistent. The goal of interpretive research is thus to formulate hypotheses which are based on empirical results and can be understood with reference to these. In further steps, such as comparative analysis, these empirically and theoretically grounded hypotheses lead towards the development of a local theory.

\footnotetext{
${ }^{1}$ See also "grand theories" (Merton 1968, p. 50ff.) and "definitive concepts" (Blumer 1954, p. 7).

${ }^{2}$ See also "middle range theories" (Merton 1968, p. 50ff.) and "sensitizing concepts" (Blumer 1954, p. 7).
} 


\subsection{Basic Concepts: The Negotiation of Mathematical Meaning}

Mathematics teaching is understood in interactionist approaches of interpretive research as an everyday "praxis of relaying mathematical knowledge" (Bauersfeld 1985 , p. 8, translated by the authors), in which an interactive negotiation of meaning takes place between participants over mathematical content. From an interactionist perspective, the individual process of learning is constituted in the social process of the negotiation of meaning. The social interaction, therefore, holds the potential to generate meanings which are new to the individual. Based on this understanding of learning and the significance of interaction in the learning of mathematics, diverse theories with rich empirical content have been developed in recent years from a foundation of "sensitizing concepts" (Blumer 1954, p. 7) - a kind of theoretical skeleton for the interaction theory of learning, which will be described below.

At the beginning of an interaction, the participants develop preliminary interpretations of the situation on the basis of their individual experiences and knowledge. Based on Thomas (1923, p. 42) and further used in pedagogical contexts by Mollenhauer (1972), these are called definitions of the situation. From an interactionist perspective, these individual definitions of the situation (Krummheuer 1992) develop in anticipation of possible attempts of other participants to interpret the situation and adjust to the other interpretations emerging in the interaction within the process of collective negotiations of meaning. The concept of the definition of the situation here refers neither to a product nor to a definition, but to an open-ended, permanent process of interpretative activity.

Thus, participants in the interaction attempt to attune their definitions of the situation to each other, ideally leading to the production of taken-as-shared meaning (Voigt 1995, p. 172), a working consensus. The term taken-as-shared meaning seeks to express that different participants' interpretations of a situation cannot ever be exactly the same but can become sufficiently aligned with each other to create an understanding between the participants concerning the objects, ideas and rules of the interaction. This understanding is assumed to be taken as shared and allows the participants to work together. The result of the participants' negotiation only is something "temporarily", an "interim", which serves as a basis for further processes of negotiation but might also be rejected or transformed as the interaction unfolds (Bauersfeld et al. 1988; Voigt 1995). The taken-as-shared meaning - the working consensus (Goffman 1959, p. 9) - is on the one hand socially constituted and, on the other, potentially novel for the individual if it pushes systematically beyond his or her interpretive capacities. The working consensus represents the 'stimulation potential' of individual cognitive restructuring processes. Through the possibility for collective generation of meaning that inheres in the social interaction, the interaction acquires an orientation function (Krummheuer 1992, p. 7, translated by the authors) for the individuals' cognitive restructuring processes. Alongside this, through the production of the working 
consensus, the social interaction also acquires a convergence function (Krummheuer 1992, p. 7, translated by the authors). In this convergence function, the taken-as-shared meanings are repeatedly negotiated in the interaction and thereby the participants' individual definitions of situations are transformed and consolidated. This allows standardized and routinized definitions of situations to develop, which the individual can reproduce in similar situations. Drawing on Goffman (1974), Bauersfeld et al. (1988) call these definitions framings (see also Krummheuer 1995). Meanings are repeatedly negotiated by participants in interactions in the mathematics classroom. Thus, ideally, mathematical ascriptions of meaning, which sustain beyond the situation (framings) are constructed, or the working consensuses, which are repeatedly collectively negotiated, 'converge' in individual mathematical framings. In relation to the learning-theoretical aspect discussed here, this leads us to conclude that learning is not the new construction of individual definitions of the situation, but the new construction or reconstruction of framings.

By learning new framings, the individual unlocks a new field of social reality. It gains a new perspective on reality, allowing new aspects and characteristics of reality to be 'seen'. (Krummheuer 1992, p. 45, translation by the authors)

However, it often happens that the framings produced by young learners either among themselves or in interaction with individuals with advanced skills are not in alignment with each other (Krummheuer 1992). Teachers interpret classroom situations based on framings from their subject-specific interactional praxis in the classroom; pupils, on the other hand, interpret situations based on framings from the environments they have experienced outside of school and in their previous school career. In order to maintain the progressive mutual negotiation of content relating to a particular theme, the differences in framing between the participants need to be coordinated. This coordination should be done by an individual who is advanced in the subject-specific interaction. This could also be a child or the teacher in school or kindergarten. While these differences in framing can make it more difficult for the participating individuals to adjust their definitions of the situations to fit each other, they also provide the "'motor' of learning" (Schütte 2014, p. 927) since, on the interactional level, they generate a certain necessity for negotiation. This necessity, however, through the effects of other strategies engaged in by the participants, either consciously or unconsciously, can also lead to the concealment of differences in framing (Krummheuer 1992). The result of such a process of negotiation is subject to some uncertainty concerning what has actually been negotiated and in the process of reaching an agreement an "intersubjectively reached relief" can be prioritised over a collectively reached acceptance of what is seen as mathematically "correct" (Krummheuer 1992, p. 113, translated by the authors). With regard to the understanding of collective learning, it can be expected that when concealing these differences in framing no collectively, interactively taken-as-shared meaning will be produced that will systematically move beyond the individual participants' abilities. This will mean that the 'reached agreement' is not able to stimulate sustainable processes of learning via participants' subjective convictions. 
Further developing the framing concept for the learning of mathematics, Schütte and Krummheuer (2017) additionally differentiate between the gaining of mathematical concepts and the development of mathematical thinking, as an introduction to a context-specific praxis of rationalisation in mathematical discourses. They differentiate analytically between the learning of mathematical content and operations and the methods of justification and explanation which build on these, although these learning forms will not appear independently of each other in practice.

After having presented the theoretical foundations of Ethnomethodology and Symbolic Interactionism and, building on this, having described the theory of interactionist approaches of interpretive classroom research with its basic terms, the procedure of the interactional analysis for reconstructing collective mathematical learning processes is described with the help of an example. Within these procedures, one can see that the terms, which have been described above, serve with the help of the interactional analysis to describe mathematical learning in collective processes of negotiation.

\subsection{Interactional Analysis}

For the analysis of collective processes of negotiation in the learning of mathematics, interactionist approaches of interpretive research in mathematics education make use of a method initially developed within these same approaches - the Interactional Analysis. As mentioned above, it was first deployed in the area of interpretive classroom research in mathematics education in studies by Bauersfeld et al. (1988) and has its origins in the Conversational Analysis in the field of Ethnomethodology (Eberle 1997; Sacks 1998; Sacks et al. 1974). Interactional Analysis allows research to reconstruct the ways in which negotiations of mathematical meaning are interactively constituted by individuals, become taken-as-shared meaning within the group and thus consolidate as individual learning in form of framings of individuals which can be reconstructed. Furthermore, it can help to reconstruct patterns and structures of verbal actions of the teacher and the students. In the following, a theoretical illustration of the Interactional Analysis is provided with examples which all refer to the interaction mentioned in the introduction.

Throughout the years, the first approaches to the Interactional Analysis within interpretive research have been modified several times by various researchers according to their specific research questions (Fetzer and Tiedemann 2018; Krummheuer 2015). Further detailed descriptions of the interactional analysis can be found in German (Krummheuer 2012; Schütte 2009).

The Interactional Analysis can include the following steps:

1. Setting of the interactional unit, 
2. Structure of the interactional unit,

3. Displaying transcripts of selected sequences

4. General description of each sequence,

5. Detailed sequential interpretation of individual utterances,

6. Turn-by-turn analysis and

7. Summary of the interpretation.

The steps 2, 4, 5, 6 and 7 are the steps in which the analysis takes place and are therefore always included (Krummheuer and Naujok 1999), whereas the steps 1 and 3 are not about analysing but help present the interaction which is to be analysed (Schütte 2009).

However, these steps of the Interactional Analysis should not be seen as a linear sequence of steps for interpreting the interaction but rather as principles for the process of interpretation in which it is possible and even sensible to repeat several of the steps (Krummheuer and Brandt 2001; Naujok 2000). Below, the steps of the Interactional Analysis will be described individually in theory and then shown for an exemplary sequence which was partly shown in the introduction already. The detailed sequential interpretation of individual utterances, however, is only presented for the first utterance before only those interpretations are presented which are left after the turn-by-turn analysis. This is mainly done because these steps are always done alternately when interpreting a sequence and presenting the entire detailed analysis would be too extensive.

\subsubsection{Setting of the Interactional Unit}

At the beginning of the analysis the setting in which the lesson takes place is briefly described so that the ensuing interpretations can be understood more easily. This may include the subject, the number of students, the arrangement of the lesson and other specifics about the beginning of the scene. The term 'interactional unit' refers to an entire lesson or to a larger part of a lesson with a connecting theme.

\section{Example: Setting of the Interactional Unit}

This interactional unit takes place at the beginning of second grade in a mathematics lesson. The students are working at different stations all on the numbers 0 100. Franka, Mira and Emilio sit down on the carpet in the classroom with a tray. On the tray, there are wooden rods of ten, a paper with the description of the station and a white box with square wooden cards with a number printed on each of them. The number cards with the tens on them are in a small transparent plastic bag and the other wooden cards are in the white box. 


\subsubsection{Structure of the Interactional Unit}

The structure of the interactional units depends on the respective research interest. It can be determined either by aspects concerning the interactional theory, e.g. the beginning and the end of a specific form of interaction, or by subject-specific or didactical subject didactic aspects, e.g. the beginning and the end of a mathematical task solving sequence. The different criteria for structuring the interactional unit can lead to varying perspectives on the material. The structure functions mainly as an overview and as a help to structure the episodes for the reader. In this paper, we will present the structure of the part of the lesson in which these three children are working on this station in order to show where the exemplary sequence is located within this interactional unit.

\section{Example: Structure of the Interactional Unit}

For this example of analysis (Table 5.2), the interactional unit is structured according to themes which emerge within the interaction of the pupils as they are working on the task given to them for this station. This includes a change of persons involved in working on this task. Therefore, the interactional unit is structured according to general aspects of mathematics teaching as there is no specific research focus for this analysis.

\subsubsection{Displaying Transcript of Selected Sequence}

In the next step, the transcript of the selected sequence is presented. If several sequences of an interactional unit are analysed, then the interaction and action in between these sequences can be described in short summaries. The transcripts are always done in spoken language, meaning they transcribe what the participants actually say, and normally include descriptions of the participants action as well. Depending on the research question this can be done in various degrees of detail. Furthermore, small pictures can be added to help understand what is meant by an action or to show what the pupils are doing with the material more easily. The rules for transcribing can also be modified depending on the research question. Here the rules for the transcript presented in this chapter are given: 
Table 5.2 Structure of interactional unit

\begin{tabular}{|c|c|}
\hline 01-09 & $\begin{array}{l}\text { The children take the rods of ten off the tray and start laying them down in one row } \\
\text { on the carpet }\end{array}$ \\
\hline \multirow[t]{2}{*}{$10-53$} & $\begin{array}{l}\text { The children distribute the wooden cards with the tens from the plastic bag } \\
\text { amongst themselves }\end{array}$ \\
\hline & $\begin{array}{l}\text { Excursus 15-33: How many cards does each child receive if one fairly } \\
\text { distributes } 10 \text { cards among } 3 \text { children? }\end{array}$ \\
\hline $54-75$ & The children place the wooden cards next to the row of rods \\
\hline $75-79$ & The children distribute the wooden cards from the white box among themselves \\
\hline $80-94$ & The children place the wooden cards next to the row of rods \\
\hline $95-124$ & $\begin{array}{l}\text { The teacher comes to the group, the children finish the task and tidy up the } \\
\text { materials. Franka and Mira receive a new task at their desks }\end{array}$ \\
\hline $125-170$ & Emilio and the teacher place the wooden cards with the tens next to the row of rods \\
\hline $171-201$ & $\begin{array}{l}\text { Emilio and the teacher place the other wooden cards from the white box next to the } \\
\text { row of rods }\end{array}$ \\
\hline
\end{tabular}

Rules for Transcription

\begin{tabular}{l|l}
\hline Bold & spoken with emphasis \\
\hline smaller & spoken quietly, whisper \\
\hline [action] & $\begin{array}{l}\text { action that takes place between two temporally separate sections of the } \\
\text { transcript }\end{array}$ \\
\hline (word) & word or sentence not unequivocally clear \\
\hline (unintelligible) & word or sentence incomprehensible \\
\hline$I$ & voice inflected up \\
\hline$I$ & voice inflected down \\
\hline$<\ldots . .(4)$ & pauses in speech in seconds \\
\hline$\#$ & The speakers (partially) talk simultaneously \\
\hline & No pause between speakers. The second speaker interrupts first speaker \\
\hline
\end{tabular}

\section{Example: Displaying Transcripts of Selected Sequences}

Mira, Franka and Emilio finish laying down the rods of ten in a row on the carpet. Mira suggests first taking the cards in the plastic bag and takes the plastic bag with the wooden cards out of the box (Table 5.3).

After the children distribute the cards among each other, they start working on the actual task given by the teacher and place the wooden cards next to the row of rods at the respective positions (see Sect. 5.5.2). 
Table 5.3 Transcript $<1-24>$

\begin{tabular}{|c|c|c|c|c|}
\hline 01 & 01:47 & & Mira & $\begin{array}{l}\text { [Takes plastic bag with cards out of the box] each one gets } \\
\text { wait. Ten divided by three }\end{array}$ \\
\hline 02 & 01:56 & & Franka & Do you know divided/. can you do divided/ \\
\hline 03 & 01:58 & & Mira & Yes \\
\hline 04 & 02:02 & & Franka & What does divided mean/ \\
\hline 05 & 02:06 & $<$ & Mira & Well divided means wait six divided divided by three is threel \\
\hline 06 & & $<$ & Emilio & $\begin{array}{l}\text { [Takes the paper with the description of the station into his } \\
\text { hand and looks at it] (unintelligible) look Mira I found a three } \\
\text { (unintelligible) }\end{array}$ \\
\hline 07 & & & Franka & eh/ \\
\hline 08 & 02:11 & & Mira & Look six divided\# \\
\hline 09 & 02:12 & $\#$ & Franka & $\begin{array}{l}\text { eh. Dividing six is three [holds left hand horizontally and } \\
\text { moves right hand, which is held vertically, up and down] }\end{array}$ \\
\hline 10 & 02:15 & & Mira & Yes \\
\hline 11 & 02:15 & & Franka & ah/that's easy \\
\hline 12 & 02:17 & & Mira & And ten divided by three/(4) doesn't work $\backslash$ yes it does. Wait \\
\hline 13 & 02:25 & & Franka & eh now I don't understand\# \\
\hline 14 & 02:27 & $\#$ & Mira & Wait \\
\hline 15 & & $<$ & Franka & Now I don't understand \\
\hline 16 & & $<$ & Mira & Ten divided by three is three six \\
\hline 17 & 02:31 & & Franka & $\begin{array}{l}\text { You cut the ten [rubs her right and left hand vertically } \\
\text { against each other] }\end{array}$ \\
\hline 18 & & $<$ & Mira & Three six nine \\
\hline 19 & & $<$ & Franka & Then five are left over. You cut\# \\
\hline 20 & 02:33 & $\#$ & Mira & $\begin{array}{l}\text { [Empties the wooden cards from the plastic bag onto the } \\
\text { carpet] so someone has to have one number more }\end{array}$ \\
\hline 21 & 02:41 & & Franka & What/me [raises right hand with extended index finger] \\
\hline 22 & $02: 43$ & & Mira & $\begin{array}{l}\text { Okay then you will get one less number there } \text { [takes the } \\
\text { white box with the other wooden cards into her hand and puts } \\
\text { it back down again] }\end{array}$ \\
\hline 23 & 02:46 & $<$ & Franka & No \\
\hline 24 & & $<$ & Emilio & $\begin{array}{l}\text { [Takes a wooden card out of the white box and puts it next to } \\
\text { the row of rods of ten in front of the second bead of the } \\
\text { second rod] }\end{array}$ \\
\hline
\end{tabular}

\subsubsection{General Description of Selected Sequence}

After presenting the transcripts, a first impression of the selected sequence is given in a general description. This general description is a coarser look which has the goal of describing the intrinsic meaning in an initial ascription and of giving an overview of the text. This is directed towards a general public who might not be interested in a detailed analysis of the selected sequence but in general matters of learning and teaching. 


\section{Example: General Description of the Selected Sequence}

At first, Mira voices a mathematical problem "ten divided by three" $<1>$. Franka then poses several questions towards Mira about "divided" which Mira first affirms and then she starts explaining the meaning of "divided" using an example $<2-8>$. Afterwards Franka gives an example on her own and both girls start working on the original mathematical problem collectively <9-19>. Mira arrives at a solution for the problem and expresses the need that one child has to receive one extra number card $<20>$. The sequence ends with Franka and Mira negotiating who will get one more card $<21-23>$. During the entire sequence, Emilio is mostly focused on the material and only once addresses Mira stating that he has "found a three" $<6>$.

\subsubsection{Detailed Sequential Interpretation of Individual Utterances}

After the general description of the activities in the chosen sequence, a detailed sequential interpretation of individual utterances is done in order to take into account the sequential organization of the conversation. According to Naujok (2000), the sequential analysis has to follow these principles:

1. The utterances, or if necessary even smaller units, are interpreted one after the other in the order of their occurrence. This makes it possible to reconstruct the development of the interaction, because in the analytic process of interpretation only events are referenced, to which the participants also had access in the respective moment of interaction.

2. Plausibility checks may only (and if the first principle is taken into consideration, only can) be done backwards.

3. Interpretations have to prove themselves in the course of the interaction. (p. 44, translated by the authors).

As described above, the interactional analysis is based on the theories of Symbolic Interactionism and Ethnomethodology. In the focus of ethnomethodological analyses are records of actual everyday social events or situations that are used to investigate how members of a society produce social orders in their actions. Ethnomethodology is not concerned with the reconstruction of action motives (Ingram 2018; Keller 2012). According to this, one principle, if not the decisive principle of the interactional analysis, is that researchers do not analyse why the participants do certain actions or what their intentions are in doing so, but only how participants act, how others react to these actions and how they interpret the actions of the other participants and then design their own actions accordingly. Analyses concerning which didactical considerations are guiding e.g. a teacher's actions, in order to explain his or her way of introducing a new topic, are therefore not the focus of the interactional analysis and, taking account of the theoretical foundations of the method, always eludes access by the researchers. In this respect, expressions 
in the analysis such as "the teacher wants to do this ..." or "the child wants to show that ..." are 'prohibited'. Based on the theoretical foundational theories, one can only analyse how the teacher carries out his or her introduction, in what form the involved children interpret these and how the mutual actions of the participants in this introduction negotiate the new mathematical topic, so that eventually something taken-as-shared can be created among all those involved. According to ethnomethodology, this no longer has to have much in common with the previously existing intention of the teacher or other participants.

In order to find alternative interpretations of individual utterances, it can be useful, following Objective Hermeneutics (Oevermann et al. 1987), to make mental context variations in order to generate additional possible interpretations in other contexts. However, the aspiration according to Oevermann et al. (1987) to, if possible, generate every possible reading seems less reasonable since this would not necessarily lead to new results but will definitely lead to an unmanageable abundance of interpretations. Therefore, the goal sequential interpretation is the maxim of preciseness corresponding to the interest of the research (Krummheuer and Brandt 2001). In particularly difficult passages, Naujok (2000) suggests to think of actions which could possibly follow an utterance to help finding further interpretations.

This detailed sequential interpretation of individual utterances, as well as the following turn-by-turn analysis following it, is normally done in analysis group settings where each of the participants receive the transcript of the sequence to be interpreted. One utterance at a time-sometimes also more or less, depending on the length of the utterances and the amount of possible interpretations - are read. The group then starts giving possible interpretations for this utterance. It is important to note, that the participants of the group do not read the entire transcript first but only read utterance by utterance in accordance to the pace of the analysis. This is done to reconstruct the sequentiality of the interaction process.

\section{Example: Detailed Sequential Interpretation of Individual Utterances}

For this example of analysis, only for the first utterance a wide variety of possible interpretations is presented in form of notes. Considering the setting of the sequence and examining possible interpretations later by using the turn-by-turn analysis, some of these interpretations are then eliminated and not given in the full interpretation of the sequence.

\begin{tabular}{l|l|l|l|l}
\hline 01 & $01: 47$ & Mira & $\begin{array}{l}\text { [takes plastic bag with cards out of the box] each one gets wait. } \\
\text { Ten divided by three }\end{array}$ \\
\hline
\end{tabular}

- This might be a mathematical problem given to the children by the teacher or the work sheet.

- There could be 10 objects which have to be distributed.

- The word problem could include a question like "How many does each one get?" 
- However, since "10:3=" is not a typical mathematical problem given in second grade, this is not likely.

- Or it might be a situation within this lesson, which is made into a mathematical problem.

- e.g., distributing real objects to the children.

Since Mira is taking cards out of a bag, she might be referring to these cards which she might later distribute equally among three children.

- If she is referring to the cards,

- it is not clear how/if she knows that there are exactly 10 cards in the bag, since she doesn't seem to count them.

Did the teacher say this when introducing the task?

Or does she know this from the context of which numbers are printed on the cards?

Or is it a guess?

- Either way, she seems to have a mental model of partitioning ${ }^{3}$ for this division where the number of people receiving something is clear and the amount which each person will receive needs to be determined.

- By saying "each one gets" she seems to be talking to someone else.

- Mira could be talking to either one of the two children present or to both

- Or she could be saying her thoughts out loud not necessarily for the other children to hear.

- "ten divided by three"

- This is a correct formulation according to mathematical terminology.

- This supports the interpretation that she has possibly already developed an idea of this arithmetic operation of division

- "wait"

- She could be saying this to herself because she is in the process of thinking.

- She could be saying this to Emilio and/or Franka that they should give her more time.

\footnotetext{
${ }^{3}$ In partition division, the number of subsets is given and the size of each subset has to be determined.
} 
- Through her action and utterance, Mira seems to organize this group work.

- Justice might be important to Mira, since she is trying to distribute the cards evenly between them.

\subsubsection{Turn-by-Turn Analysis}

By then doing a turn-by-turn analysis, the diverse alternative interpretations of the previous sequential analysis are limited following the works of Conversational Analyses and on the basis of the sequential organization of the conversation. The goal is to arrive at conclusive interpretations of consecutive actions: "The question of the turn-by-turn analysis therefore is: How other participants of the interaction react to an utterance, how do they seem to interpret the utterance, how is it developed further collectively, what is made of the situation collectively?" (Naujok 2000 , p. 46, translated by the authors). The detailed sequential interpretation and the turn-by-turn analysis were interwoven and are therefore now presented in a coherent text.

\section{Example: Turn-by-Turn Analysis}

At the beginning of the presented sequence, Mira takes the plastic bag with the cards from the box and says "each one gets wait. ten divided by three" $<1>$. With this utterance Mira could be mathematizing a problem from the situation of trying to distribute the cards evenly. The ten may then be referring to the amount of cards which are in the plastic bag. Why she knows that there are exactly ten cards in the plastic bag, remains unclear. Since the three children are working on this station together, the divisor 3, could refer to the amount of children to which the amount of supposedly ten cards is to be distributed to evenly. The beginning of the utterance $<1>$ "each one gets" suggests that Mira perceives the division task within the mental model of partitioning. 4 The amount of the subset to be created in this case is predefined by the three children and the question arises how many cards are in a subset.

The task "10:3=" as a division with a remainder, however, is not a typical math problem for a second grade. This supports the interpretation that the problem emerges from the situation, is developed by Mira and is not a task given by the teacher or written on the work sheet. Nevertheless, the formulation "ten divided by three" $<1>$ is a correct formulation according to mathematical terminology. This suggests that Mira has possibly already developed an idea of this arithmetic operation of division. The attempt to distribute the ten cards to three persons is an indicator that Mira takes the previous instruction given by the teacher, to include Emilio in the group work, seriously and that she might later distribute the cards evenly so that everyone can participate in the group work equally. By saying

\footnotetext{
${ }^{4}$ The German word for partitioning is "verteilen" which is also used for distributing e.g. cards.
} 
"wait" $<1>$, Mira could be addressing Franka and/or Emilio in order to gain time so that she can state this sophisticated formulation correctly.

Before Mira expresses a solution to her task, Franka says "do you know divided. can you do divided/" $<2>$. This seems to be a turn on Mira's utterance in $<1>$, however, it may also be directed towards Emilio. The sentences formulated by Franka here are rather incomplete. The reason for this could be that she is surprised or that she only vaguely knows what the term "divided" means and therefore cannot incorporate the term in a coherent meaningful statement. This uncertainty, as well as the fact that Franka does not directly solve the task ten divided by three, supports the assumption that she herself cannot calculate "divided" and may also be unable to establish a connection to the meaning of the term "divided." She may therefore be amazed that Mira seems to be capable doing so. However, the term does not seem to be completely foreign to her, as she connects it to something that one can "know" or "can do". Franka's use of "divided" may also indicate that she uses it as the term for division. For example, she might already have heard it from the teacher, as the term for "divided" in German is often used as a didactical term for the basic arithmetic operation of division in primary school everyday teaching. However, according to this interpretation she would not be using the term grammatically correct in neither statement. With "do you know divided" $<2>$, Franka could rather be asking for the technical term "divided" or for the meaning of "divided" in the sense of "do you know what divided means". "Can you do divided" $<2>$, in the sense of "you can calculate divided by", sounds more like a question about the skill of applying the division. As she asks this second question, she seems to at least associate the term "divided" with an action. Furthermore, the participle of the verb "to divide" - divided - a would always be used for the description of the action of a division. ${ }^{5}$

She may be asking these two questions in immediate succession because she is making the first question more precise or modify it with the second question. She might do this because she realizes that "divided" is not something that you need to know, but rather is something you have to be able to do or perform. On the other hand, she might also rephrase the first question because she realizes that for the distribution of the cards, it would be enough for Mira to simply solve the task without explaining the concept. Lastly, she might modify her first question because Mira does not react during the pause in between her utterances and Franka asks again and therefore increasingly demands an answer. This could be out of a real interest, as she may not know the answer, or it could be a kind of interrogation in the style of a teacher.

Mira reacts to Franka's questions with "yes" $<3>$. This short answer may indicate that she herself is still thinking of her 'task' and therefore limits her communication to the bare minimum. However, it could also be interpreted as Mira being very sure and "yes" therefore as the direct answer to one or both of the questions. Her utterance can either be interpreted as knowing what division is, i.e.,

\footnotetext{
${ }^{5}$ In English, this is a past participle. In German, she uses the "Partizip II".
} 
knowing the concept, but possibly not being able to divide; as being able to divide, but not being able to further explain what division is - hence only the short answer; or as being able to do both.

In $\langle 4\rangle$, Franka asks again "what does divided mean/". Repeating her question with the term "means" indicates that Franka's question was not a rhetorical question before, that she does not know the answer herself, and that she has a genuine interest in the answer to the question of what is meant by the idea of "divided." Mira had answered Franka's questions of $<2>$ with "yes" but failed to answer to the implicit request for an explanation or the naming of a result. Another interpretation could still be that Franka acts, as mentioned above, in the style of a teacher and now 'asks' Mira if she really knows what division is. Mira might now explain the term or idea of division in response to the question with a general explanation or with a concrete example, possibly with her own task (10:3).

Mira then says, "well divided means wait six divided divided by three is three" $<5>$. At first glance, it does not become clear what Mira is saying with this utterance. By using "well", she seems to respond to Franka's question but paraphrases Franka's "means" with another German word for "means". She interrupts her sentence with "wait", which may indicate that she is considering how she can answer the question, as she may well know what "divided" means but cannot easily explain it in words. This may also be the reason why Mira now uses a concrete example to explain "divided" to Franka. By doing so, she reacts more to the second question "can you do divided/" than to "do you know divided". She might have a framing of division which is in alignment with the concept of division generally common within the domain of mathematics, and merely miscalculates and therefore comes to the result three. She could also have simply made a slip of the tongue by saying three instead of two-for both the first or the second "three". In this case, she would then have to make a repair afterwards, meaning revise her utterance, if this incorrect wording has negative effects on the following interaction. However, she could also have a differing framing of division and refer to decomposing a number, meaning breaking up the number six into three plus three, or refer to dividing as halving. This would mean that for her dividing ten by three equals five. Franka could interpret her utterance in this way as well. A final interpretation of Mira's utterance is that "three" is not the result of her calculation but a repetition of the first "three" in order to continue calculating with it. Additionally, it is not clear why Mira uses six as the dividend as it could be by chance or a typical mathematical problem which she has already solved previously, e.g. when doubling numbers. Or six could be an intermediate result in the process of her solving the first problem — e.g. by counting by threes "three, six, nine"-and now she uses it to explain division to Franka.

While Mira speaks, Emilio picks up the description of the station and looks at it. Then he utters something incomprehensible before he says "look Mira I found a three" $\langle 6\rangle$. This statement could be interpreted as him not being able to completely follow the conversation of Mira and Franka or as him following it and now trying to participate in the conversation and possibly even trying to support his two classmates in the search for the meaning of division. He is trying to attract attention with 
"look", as Mira and Franka seem to be talking to each other and not to Emilio, as interpreted in $\langle 1\rangle$. Him mentioning the number three allows for various interpretations. He could be taking up Mira's "three" $(<1,6>)$, which indicates that he followed the conversation attentively, or he could have randomly read the number on the description of the station regardless of the previous utterances. However, he could also point out that he has found the solution to the above task 10:3. It is also possible that he has found the card with the number three and is pleased because he can arrange the number three on the row of rods-forming a type of number line, which would correspond to the actual task of the station.

Franka now seems to be responding to Mira's explanation and her "eh/" <7> can be interpreted as indicating that she cannot follow the explanation or does not understand it. Mira repeats the beginning of her mathematical example $<5>$ "look six divided\#" $<8>$. The "look" can be interpreted as the beginning of an explanation and thus as a direct turn on the statement of Franka. Another interpretation could be a direct reference to Emilio's utterance, which also began with "look" and thus might be a negotiation between Emilio and Mira about what is currently in the focus of interaction.

Franka interrupts Mira with the statement "eh. dividing six is three" $<9>$, holding her left hand horizontally and moving her right hand vertically up and down. The "eh" could be related to the fact that she does not understand why Mira mentions six as the ten was supposed to be divided previously. However, it could also be related to the solution "three", which she cannot understand or which she does not agree with. That after a brief pause, in which she is possibly trying to understand Mira's utterance, she then says "dividing six is three" could be a repetition of Mira's utterance in $<5>$. On the one hand, this repetition could be interpreted as a repetition within the process of trying to understand Mira or as questioning the utterance.

At this point, Franka could solve the task "dividing six" herself and come to the result three. In contrast to Mira's utterances and her own questions, Franka now uses the gerund infinitive "dividing" instead of "divided". 6 Combined with the movement of her hand, one could derive from her utterance an idea of dividing as "cutting in half/halving", which she may only be developing in this moment by trying to understand Mira's problem. With that, Franka has moved away from the original problem of distributing the cards to three children and is trying to comprehend the meaning of "divided/dividing" introduced by Mira into the interaction.

Mira answers with "yes" $<10>$ which could, on the one hand, support the interpretation that she accidently made a mistake in $\langle 5\rangle$ and actually wanted to say the solution "three" for the task "six divided by two". On the other hand, one could also interpret that Mira here confirms Franka's idea of dividing as halving.

However, since she explicitly says "divided by three" earlier, Mira seems to already differentiate the idea of dividing as halving and the idea of dividing into more than two subsets. However, at this point this does not become clear for Franka

\footnotetext{
${ }^{6}$ In German, she uses the infinitive instead of the "Partizip II".
} 
and could lead to difficulties in understanding later on. So far, it can be observed that Mira and Franka, despite the existing possible variety of mathematical interpretations at the interactional level, have negotiated a taken-as-shared meaning with a certain fit and continue on this basis.

With the utterance "ah/that's easy" $<11>$, Franka supports the interpretation that her utterance in $\langle 9\rangle$ was a question for Mira, with whom she was evaluating her idea of dividing, and interprets Mira's answer in $\langle 10\rangle$ as a confirmation. It remains unclear what Franka calls "easy" - the concrete calculation or the general idea of division. Therefore, this utterance does not align with the interpretation of $\langle 2>$ and $\langle 4\rangle$ that Franka acts in the style of a teacher and her questions are merely testing Mira but underlines the interpretation that it was a sincere question.

Mira returns to the actual task and says "and ten divided by three/(4) doesn't work $\backslash$ yes it does. wait" $<12>$. After formulating the mathematical problem, she pauses which may indicate that she is trying to solve it in her head at the moment of speaking. By saying "doesn't work", she may indicate that she cannot find a suitable solution, and thus assumes that the task is generally not solvable. This reinforces the interpretation that Mira has developed a relatively differentiated framing of division and can distinguish between dividing into two subsets (halving) and dividing into more than two subsets, since the set ten could be easily divided into two subsets of five elements each. For other participants in the interaction, however, the utterance could possibly also be interpreted as consistent with the idea of halving. Mira could thereby say that halving in two subsets "does not work", since they are three and not two children. With the "yes it does" Mira seems to point out that she does have an idea for the solution of the tasks. However, she does not seem to have these ready at hand but has to think again and calls for time by saying "wait."

Franka reacts with "eh now I don't understand\#” <13>. Against the background of her previous definition of the situation of dividing as halving, this utterance can be interpreted as an astonishment why the ten cannot be halved in exactly the same way into two subsets as the six - in the case of the ten with five elements each. But Franka could also already be confused by the phrase "ten divided by three" because in the idea of halving one only says "divided by" and does not include the divisor. She might also be wondering about how halving helps them distribute the cards among three people. Mira interrupts Franka with "wait" $<14>$ and asks for more time. This could be interpreted in the sense of "I cannot listen to you right now or explain it to you because I am still thinking about it." However, Franka does not wait and repeats her statement again $\langle 15\rangle$. Simultaneously, Mira now starts verbalizing her calculation "ten divided by three is three six" $\langle 16\rangle$.

On the one hand, this verbalization could serve as a support for herself to help her concentrate despite the intervening remarks and therefore be directed towards herself, or it could be interpreted as an explanation for Franka. Because of the expression "is three six", no longer an idea of dividing as halving can be interpreted here, but a mental model of quotitioning or partitioning. For solving this problem, she seems to use the inverse operation here by going through the three times table or by counting by threes. This suggests that Mira already has the assumption that 
when one divides ten by three each subset contains at least three elements, and she now has to only determine how many remain if she distributes three cards to each child (mental model of partitioning). But it could also be part of the process of trying out, and three at this point is a random number she picked with which she now tests how many subsets of three elements can be generated from the set ten (mental model of quotitioning).

Franka responds to Mira's statement by verbally and gesturally explicating her idea of division built up to that point "you cut the ten [rubs her right and left hand vertically against each other]" $<17>$. This gesture together with the verb "cut" supports the interpretation that Franka has created a definition of the situation within the interaction in which dividing is understood as halving and in which there is not yet a differentiated framing of dividing by a divisor larger than two. Her solution of the problem would therefore have to be five. At this point, differences in the framing of the two girls are seen, which initially did not come to fruition-also due to imprecise verbal formulations - and enabled a taken-as-shared meaning to develop.

The next two utterances $(<18>$ and $<19>)$ take place simultaneously. This indicates that both are still caught in their own thoughts and cannot properly accommodate each other's utterances. Mira continues her times table with "three six nine" $<18>$ or counts by threes and does not seem to follow Franka's incidental remark correctly. Franka, on the other hand, pursues her idea of halving visualized by the cutting "then five are left over. you cut\#" $<19>$. The phrase "then five are left over" may here be interpreted also in the sense of an idea of subtraction or underlines the idea of sharing (which is the same word as dividing in German), e.g. with a sibling where in most cases one half is given away. With the subsequent repetition of "you cut", Franka may be emphasizing her practical idea of sharing. However, she could also be pointing out that the resulting subset of 5 must now be "cut" or divided again so that (at least) three subsets are created.

Mira interrupts Franka's explanation, as she seems to have now arrived at a solution. She empties the wooden cards from the plastic bag onto the carpet and says "so someone has to have one number more" $<20>$. She does not explain the process of arriving at her solution, which supports the interpretation that her previous utterances $<12,16,18>$ were rather directed towards herself and not meant as an explanation for Franka. The utterance "one number more" can be interpreted as one number card more. With this, Mira has successfully distributed the ten number cards to three children with the help of a mathematical modeling and the solution of a division problem with a remainder. Whether her result is correct, she could now possibly check by practically distributing the number cards.

Franka seems surprised by the result of Franka, reacts with "what/me" $<21>$ and raises her right hand with her extended index finger. In the context of the now practical distribution situation, the mathematical differences seem to take a back seat for her, which is underlined by the gesture of signaling. This can be interpreted as a clear demand for her wanting to receive the additional number card. She thus leaves the negotiation of the mathematical content concerning the idea of division and does not question Mira's solution. Thus, the veiled differences in framing 
remain. Another possible interpretation could be that Franka's utterance in $<21>$ is the beginning of the attempt to introduce her idea of the solution of the problem into the interaction.

Mira responds to Franka's utterance with "okay then you will get one less number therel" $<22>$. For her too, a fair distribution between the children seems to be the main focus here. She does not add an explanation of her approach to the interaction.

Franka contradicts Mira's statement with "no" $<23>$. At the same time, Emilio becomes active again for the first time by taking a number card out of the box and placing it on the row of rods. At this point, he ignores the distribution negotiated in the interaction because he does not take a number of the ten numbers which Mira has just successfully distributed, but one of the other cards.

\subsubsection{Summary of the Interpretation}

In the last step of the Interactional Analysis, the diversity of interpretations is reduced in the summary of the interpretation where the interpretations of the sequences, which can best be justified, are summarized. This summary serves as a basis for generating theory as it represents the transition between the detailed interpretations of the Interactional Analysis and the first theorisations based on these interpretations. The research question, therefore, determines under which focus the interpretations are summarised. Often in publications, only these summaries of the interpretations are given, since the detailed interpretations are very extensive and can be hard to read due to the diversity of interpretations.

The focus of this summary is on the subject-specific processes of negotiation concerning division between Mira and Franka and the differences in framing emerging within the interactions. The summary thus again focuses on the central ideas of the interactional theory - the negotiation of meaning and the construction of framings.

\section{Example: Summary of the Interpretation}

In the situation, Mira creates a mathematical model in form of a division problem which helps her distribute the cards fairly to the three children in the group ("ten divided by three" $<1>$ ). Franka reacts in astonishment and asks Mira if she can do "divided". Mira confirms this and upon a renewed inquiry from Franka for the meaning of "divided", Mira gives an example: "six divided divided by three is three" $<5>$. Franka, on the basis of this example, seems to develop a definition of the situation which equates dividing with halving. This is also becomes clear through her gestures. Franka then checks her hypothesis and Mira confirms it. As a result, Franka seems to be reassured in this definition of the situation. At this point in the interaction, it seems possible to reconstruct a taken-as-shared meaning between the two girls. 
In the further course, however, one can see that the framings of the girls with regard to the mathematical operation of dividing/division are different. Mira seems to already have cultivated a very differentiated mathematical framing of division, and apparently understands dividing both as halving and as division by a divisor greater than two. Franka's framing, on the other hand, seems very much related to the everyday idea of sharing meaning dividing into two halves and thus seems to have developed a less differentiated framing, according to which she understands dividing exclusively as halving. Moreover, the differences in framing that occur may be intensified or not resolved by the children, because the everyday connotation of the term 'dividing' does not coincide with the technical language and thus the varying use of the term 'dividing' remains implicit for the children involved. Thus, Mira may consciously not contradict Franka, because the term 'dividing' can be interpreted appropriately with regard to the framings of both everyday language and mathematics. Having a more everyday framing, 'dividing' can be interpreted as always implying halving or splitting into two halves. However, dividing can also be understood as dividing any amount into different numbers of subsets. Thus, Franka's solution dividing ten equals five is correct when having an everyday framing of halving and leads to a contradiction only if the divisor does not equal two and a mathematical framing is used.

Mira comes back to the original division problem and first determines that it is not solvable but then has an idea and starts to calculate. At the same time, Franka expresses her lack of understanding, however, it is unclear whether this is about Mira's utterance of unsolvabilty or in the general sense about the operation of dividing. Mira frames the division as a process of halving, and therefore arrives at the result 5 for the dividend 10 . The divisor 3 remains unnoticed by her.

Mira, on the other hand, still tries to solve the division problem 10:3 by counting the saying the times three table or by counting by threes "three six nine" $<18>$. Her idea for the solution is successful and she arrives at the conclusion that there is a remainder of one. She directly transfers this solution to the specific situation and says that one person has to get one more card. She does not deal with the differences between Franka and her and starts organizing the next step in the group work. From this moment on, Franka is no longer interested in a resolution of the differences between her framing of division and that of Mira. She accepts Mira's solution without question and the concrete distribution of the cards comes to the fore. Emilio, the third child in the group work, is also considered for distribution of the cards, but in the course of the conversation is only a listener, as Franka and Mira lead a dyadic interaction.

\subsection{Conclusion}

Through the Interactional Analysis, the thematic development of the interaction was analysed on the basis of the participants' negotiations of meaning. The interaction used as an example in this chapter is only short, thus opportunities for learning 
which may develop for the participating children can only be reconstructed to some extent. However, the potential for learning opportunities in interactions like these can be seen for both children in the negotiation on mathematical meaning. For example, Mira, as the child with the more differentiated framing, has the opportunity to not only apply her framing, but through the negotiation to reflect on her own framing and try to understand Franka's framing. Franka, on the other hand, as the child with the framing less differentiated, has the opportunity to expand her framing by negotiating a framing more functional in the domain of mathematics.

At the end of the analysis processes, a very dense description of the learning processes within the collective negotiation processes is obtained. However, how can the scope of such interpretative research finding be transferred from the status of pure case analyses to greater generalizability in the sense of developing local theories (Merton 1968). It requires the development of a "research style" (Bohnsack 2007, p. 198), which favors theoretical constructions. For this, a central element of the research style of grounded theory, the comparative analysis- "constant comparative method" (Glaser and Strauss 1967; Strauss and Corbin 1994) — can be referred to. The comparative analysis is a method of creating comparison groups which can be applied at all levels of the research process and favors theoretical constructions (see also the description of various ways of making inferences in Schütte (2009) or Krummheuer (2002) for a more specific description of abduction). It not only describes a particular step in the analysis within the research process, but serves as a specific methodical approach throughout the entire research process. At the beginning, in comparative analysis, the aim is to depict the specificity of the segment of reality. Thereafter, the specificity of the respective cases in their relation to each other is examined via a suitable theoretical selection. By means of omparesons, criticism can be rebutted from the deductive-nomological research direction that the results obtained from qualitative works are only valid for individual cases and thus of little relevance. Comparisons lift the analyses of the research beyond a status of case analyses. The systematic and continuous comparison of cases among each other during the entire research process brings dimensions that would not be valid if the cases were considered purely. Thus, by means of comparisons, an extended "conceptual space", in which one can search for solutions or generate possible theoretical elements, is created.

Accompanying this process, the results gathered in the summaries are also compared to theory. From the second scene onward, these reflections on theory of each analysis are compared with the reflections on theory of scenes which have already been analysed. These comparative analyses can reveal structural inconsistences as well as phenomena which cannot be explained by theory and in a further step will lead to an expansion or redesign of existing theory. By doing so, inconsistences of existing theory are discovered and unique phenomena are mapped out. 


\section{Appendix}

\section{Transcript in German}

\begin{tabular}{|c|c|c|c|c|}
\hline 09 & $01: 47$ & & Mira & $\begin{array}{l}\text { [nimmt Plastiktüte mit Kärtchen aus der Box] Jeder kriegt } \\
\text { warte zehn geteilt durch drei }\end{array}$ \\
\hline 10 & 01:56 & & Franka & weißt du geteilt/. kannst du geteilt/ \\
\hline 11 & 01:58 & & Mira & $\mathrm{Ja}$ \\
\hline 12 & 02:02 & & Franka & was bedeutet geteilt/ \\
\hline 13 & 02:06 & $<$ & Mira & also geteilt heißt warte sechs geteilt geteilt durch drei ist dreil \\
\hline 14 & & $<$ & Emilio & $\begin{array}{l}\text { [nimmt das Blatt mit der Stationsbeschreibung in die Hand } \\
\text { und betrachtet es] (unverständlich) guck mal Mira ich habe } \\
\text { eine drei gefunden (unverständlich) }\end{array}$ \\
\hline 15 & & & Franka & hä/ \\
\hline 16 & 02:11 & & Mira & guck mal sechs geteilt\# \\
\hline 17 & 02:12 & $\#$ & Franka & $\begin{array}{l}\text { hä. sechs teilen ist drei [hält linke Hand waagrecht und } \\
\text { bewegt rechte senkrecht gehaltene Hand nach oben und } \\
\text { unten] }\end{array}$ \\
\hline 18 & 02:15 & & Mira & Ja \\
\hline 19 & 02:15 & & Franka & $\mathrm{ah} /$ das ist ja einfach \\
\hline 20 & 02:17 & & Mira & und zehn geteilt durch drei/(4) geht nichtl doch. warte \\
\hline 21 & 02:25 & & Franka & hä versteh ich jetzt nicht\# \\
\hline 22 & 02:27 & $\#$ & Mira & Warte \\
\hline 23 & & $<$ & Franka & versteh ich jetzt nicht \\
\hline 24 & & $<$ & Mira & zehn geteilt durch drei ist drei sechs \\
\hline 25 & 02:31 & & Franka & $\begin{array}{l}\text { man schneidet die Zehn durch [reibt rechte und linke Hand } \\
\text { senkrecht aneinander] }\end{array}$ \\
\hline 26 & & $<$ & Mira & drei sechs neun \\
\hline 27 & & $<$ & Franka & dann bleiben fünf übrig. man schneidet\# \\
\hline 28 & 02:33 & \# & Mira & $\begin{array}{l}\text { [schüttet die Holzkärtchen aus der Plastiktüte auf den } \\
\text { Teppich] also jemand muss eine Zahl mehr haben }\end{array}$ \\
\hline 29 & 02:41 & & Franka & was/ich [hebt rechte Hand mit gestrecktem Zeigefinger] \\
\hline 30 & 02:43 & & Mira & $\begin{array}{l}\text { ok dann kriegst du da eine Zahl weniger\[nimmt die weiße } \\
\text { Box mit den weiteren Holzkärtchen in die Hand und stellt sie } \\
\text { wieder hin] }\end{array}$ \\
\hline 31 & $02: 46$ & $<$ & Franka & Nein \\
\hline 32 & & $<$ & Emilio & $\begin{array}{l}\text { [nimmt ein Holzkärtchen aus der weißen Box und legt es an } \\
\text { die Zehnerstangen-Kette vor die zweite Kugel der zweiten } \\
\text { Stange] }\end{array}$ \\
\hline
\end{tabular}




\section{References}

Bauersfeld, H. (1985). Ergebnisse und Probleme von Mikroanalysen mathematischen Unterrichts. In W. Dörfler, \& R. Fischer (Eds.), Empirische Untersuchungen zum Lehren und Lernen von Mathematik (pp. 7-25). Wien: Hölder-Pichler-Tempsky.

Bauersfeld, H., Krummheuer, G., \& Voigt, J. (1988). Interactional theory of learning and teaching mathematics and related microethnographical studies. In H.-G. Steiner, \& A. Vermandel (Eds.), Foundations and methodology of the discipline mathematics education (pp. 174-188). Antwerp: University of Antwerp.

Blumer, H. (1954). What is wrong with social theory? American Sociological Review, 19(1), 3-10.

Blumer, H. (1969). Symbolic interactionism. Englewood Cliffs, NJ: Prentice-Hall.

Bohnsack, R. (2007). Rekonstruktive Sozialforschung. Einführung in qualitative Methoden (6th ed.). Opladen: Barbara Budrich.

Cobb, P., \& Bauersfeld, H. (Eds.). (1995a). The emergence of mathematical meaning. Interaction in classroom cultures. Hillsdale, $\mathrm{NJ}$ : Lawrence Erlbaum.

Cobb, P., \& Bauersfeld, H. (1995b). Introduction: The coordination of psychological and sociological perspectives in mathematics education. In H. Bauersfeld, \& P. Cobb (Eds.), The emergence of mathematical meaning. Interaction in classroom cultures (pp. 1-16). Hillsdale, NJ: Lawrence Erlbaum.

Eberle, T. S. (1997). Ethnomethodologische Konversationsanalyse. In R. Hitzler, \& A. Honer (Eds.), Sozialwissenschaftliche Hermeneutik (pp. 245-281). Opladen: Leske + Budrich.

Fetzer, M., \& Tiedemann, K. (2018). The interplay of language and objects in the process of abstracting. In J. Moschkovich, D. Wagner, A. Bose, J. Rodrigues Mendes, M. Schütte (Eds.), Language and communication in mathematics education (pp. 139-155). Cham: Springer.

Garfinkel, H. (1967). Studies in ethnomethodology. Englewood Cliffs, NJ: Prentice-Hall.

Glaser, B., \& Strauss, A. (1967). The discovery of grounded theory. Strategies for qualitative research. New York: Aldine.

Goffman, E. (1959). The presentation of self in everyday life. New York: Doubleday.

Goffman, E. (1974). Frame analysis. An essay on the organization of experience. Cambridge: Harvard University Press.

Ingram, J. (2018). Moving forward with ethnomethodological approaches to analysing mathematics classroom interactions. International Journal on Mathematics Education-ZDM (in press).

Kelle, U. (1994). Empirisch begründete Theoriebildung. Zur Logik und Methodologie interpretativer Sozialforschung (2nd ed.). Weinheim: Deutscher Studienverlag.

Keller, R. (2012). Das interpretative Paradigma. Wiesbaden: Springer VS.

Krummheuer, G. (1992). Lernen mit Format. Elemente einer interaktionistischen Lerntheorie. Diskutiert an Beispielen mathematischen Unterrichts. Weinheim: Deutscher Studien Verlag.

Krummheuer, G. (1995). The ethnography of argumentation. In H. Bauersfeld, \& P. Cobb (Eds.), The emergence of mathematical meaning. Interaction in classroom cultures (pp. 229-269). Hillsdale, NJ: Lawrence Erlbaum.

Krummheuer, G. (2002). The comparative analysis in interpretive classroom research in mathematics education. In J. Novotná (Ed.), European Research in Mathematics Education II: Proceedings of the Second Conference of the European Society for Research in Mathematics Education (CERME 2, 24-27 February 2001) (pp. 339-346). Mariánské Lázně: Czech Republic: Charles University, Faculty of Education and ERME.

Krummheuer, G. (2004). Wie kann man Mathematikunterricht verändern? Innovation von Unterricht aus Sicht eines Ansatzes der Interpretativen Unterrichtsforschung. Journal für Mathematik-Didaktik, 25(2), 112-129.

Krummheuer, G. (2012). Interaktionsanalyse. In F. Heinzel (Ed.), Methoden der Kindheitsforschung. Ein Überblick über Forschungszugänge zur kindlichen Perspektive (2nd ed.) (pp. 234-247). Weinheim, Basel: Beltz-Juventa. 
Krummheuer, G. (2013). The relationship between diagrammatic argumentation and narrative argumentation in the context of the development of mathematical thinking in the early years. Educational Studies in Mathematics, 84(2), 249-265.

Krummheuer, G. (2015). Methods for reconstructing processes of argumentation and participation in primary mathematics classroom interaction. In A. Bikner-Ahsbahs, C. Knipping, \& N. Presmeg (Eds.), Approaches to qualitative research in mathematics education (pp. 51-74). Dordrecht: Springer.

Krummheuer, G., \& Brandt, B. (2001). Paraphrase und Traduktion. Partizipationstheoretische Elemente einer Interaktionstheorie des Mathematiklernens in der Grundschule. Weinheim, Basel: Beltz Verlag.

Krummheuer, G., \& Naujok, N. (1999). Grundlagen und Beispiele Interpretativer Unterrichtsforschung. Opladen: Leske + Budrich.

Lerman, S. (2000). The social turn in mathematics education research. In J. Boaler (Ed.), Multiple perspectives on mathematics teaching and learning (pp. 19-44). Westport, CT: Ablex.

Merton, R. K. (1968). Social theory and social structure. New York: The Free Press.

Miller, M. H. (1986). Kollektive Lernprozesse: Studien zur Grundlegung einer soziologischen Lerntheorie. Frankfurt, Main: Suhrkamp.

Mollenhauer, K. (1972). Theorien zum Erziehungsprozeß. München: Juventa.

Naujok, N. (2000). Schülerkooperation im Rahmen von Wochenplanunterricht. Analyse von Unterrichtsausschnitten aus der Grundschule. Weinheim: Dt. Studien-Verl.

Oevermann, U., Allert, T., Konau, E., \& Krambeck, J. (1987). Structures of meaning and objective hermeneutics. In V. Meja, D. Misgeld, \& N. Stehr (Eds.). Modern German sociology. European perspectives: A series in social thought and cultural criticism (pp. 436-447). New York: Columbia University Press.

Sacks, H. (1998). Lectures on conversation (3rd ed.). Malden, Ma: Blackwell.

Sacks, H., Schegloff, E. A., \& Jefferson, G. (1974). A simplest systematics for the organization of turn-taking for conversation. Language, 50, 696-735.

Schütte, M. (2009). Sprache und Interaktion im Mathematikunterricht der Grundschule. Zur Problematik einer Impliziten Pädagogik für schulisches Lernen im Kontext sprachlich-kultureller Pluralität. Münster: Waxmann.

Schütte, M. (2014). Language-related learning of mathematics. A comparison of kindergarten and primary school as places of learning. ZDM Mathematics Education, 46(6), 923-938.

Schütte, M., \& Krummheuer, G. (2017). Mathematische Diskurse im Kindesalter. In U. Kortenkamp, \& A. Kuzle (Eds.), Beiträge zum Mathematikunterricht 2017 (pp. 877-880). Münster: WTM-Verlag.

Sfard, A. (2008). Thinking as communicating: Human development, development of discourses, and mathematizing. Cambridge: Cambridge University Press.

Solomon, Y. (2009). Mathematical literacy: Developing identities of inclusion. New York: Routledge.

Strauss, A., \& Corbin, J. (1994). Grounded theory methodology. In N. K. Denzin, \& Y. S. Lincoln (Eds.), Handbook of qualitative research (pp. 273-285). Thousand Oaks: Sage.

Thomas, W. I. (1923). The unadjusted girl: With cases and standpoint for behavior analysis. Boston: Little, Brown, and Co.

Tiedemann, K., \& Brandt, B. (2010). Parents' support in mathematical discourses. In U. Gellert, E. Jablonka, \& C. Morgan (Eds.), Proceedings of the 6th International Conference on Mathematics and Proceedings of the 6th International Conference on Mathematics Education and Society (pp. 457-468). Berlin, Deutschland (20-25 March 2010).

Turner, J. H. (1988). A theory of social interaction. USA: Standford University Press.

Voigt, J. (1995). Thematic patterns of interaction and sociomathematical norms. In H. Bauersfeld, $\&$ P. Cobb (Eds.), The emergence of mathematical meaning. Interaction in classroom cultures (pp. 163-201). Hillsdale, NJ: Lawrence Erlbaum. 
Open Access This chapter is licensed under the terms of the Creative Commons Attribution 4.0 International License (http://creativecommons.org/licenses/by/4.0/), which permits use, sharing, adaptation, distribution and reproduction in any medium or format, as long as you give appropriate credit to the original author(s) and the source, provide a link to the Creative Commons license and indicate if changes were made.

The images or other third party material in this chapter are included in the chapter's Creative Commons license, unless indicated otherwise in a credit line to the material. If material is not included in the chapter's Creative Commons license and your intended use is not permitted by statutory regulation or exceeds the permitted use, you will need to obtain permission directly from the copyright holder.

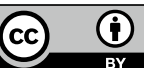

